\title{
INFLUÊNCIA DA CONTAGEM DE CÉLULAS SOMÁTICAS SOBRE O IMPACTO ECONÔMICO DA MASTITE EM REBANHOS BOVINOS LEITEIROS
}

\author{
M.A. Lopes $^{1 *}$, F.A. Demeu ${ }^{1 * *}$, G.M. da Costa ${ }^{1}$, C.M.B.M. da Rocha ${ }^{1}$, \\ L.R. de Abreu ${ }^{2}$, G dos Santos ${ }^{1 * *}$, A. Franco Neto ${ }^{1 * * *}$ \\ ${ }^{1}$ Universidade Federal de Lavras, Departamento de Medicina Veterinária, CP 3037, CEP 37200-000, Lavras, \\ MG, Brasil. E-mail: malopes@dmv.ufla.br
}

\section{RESUMO}

\begin{abstract}
Os objetivos desta pesquisa foram analisar e quantificar a influência da contagem de células somáticas (CCS) sobre o impacto econômico da mastite. A pesquisa foi realizada por meio de simulação no sistema computacional CU\$TO MASTITE, considerando rebanhos leiteiros com média de 250.000; 500.000; 750.000 e 1.000.000 células somáticas/mL de leite. Foram consideradas como prevenção as despesas com monitoramento (cultura e antibiograma, CCS do tanque e CCS individual), pré e pós dipping, vacinação, tratamento de vacas secas e manutenção de ordenhadeira. Como medidas curativas foram considerados os tratamentos com casos clínicos, cuja percentagem foi de $7 \%$ das vacas em lactação. O impacto da mastite foi estimado como sendo o total em perdas acrescido das despesas com prevenção e tratamento de casos clínicos. O aumento da contagem de células somáticas no tanque influenciou diretamente no impacto econômico da mastite. O elevado impacto evidencia a necessidade de monitoramento da mastite clínica e subclínica e adoção de medidas preventivas para diminuir os impactos ocasionados. As despesas com prevenção representaram, no máximo, 10,8\% do impacto econômico, o que demonstra vantagens em investir nessa prática, pois irá contribuir significativamente para diminuição da CCS no tanque e, consequentemente, para reduzir o impacto econômico da mastite.
\end{abstract}

PALAVRAS-CHAVE: Bovinocultura leiteira, economia, qualidade doleite, sanidadeanimal, simulação.

\section{ABSTRACT}

INFLUENCE OF SOMATIC CELL COUNTING IN THE ECONOMIC IMPACT OF MASTITIS IN DAIRY HERDS. The objectives of this research were to investigate and quantify the influence of the somatic cell count (SCC) on the economic impact of mastitis. The work was carried out by means of data simulation in CU\$TO MASTITE software system, taking into account dairy herds with 250,000; 500,000; 750,000 and 1,000.000 cells/mL of milk. Were considered as prevention expenses on monitoring (culture and antibiogram, bulk tank SCC and individual SCC) pre and post dipping, vaccination, treatment of dry cows and maintenance of milking machine. As curative measures, treatment of clinical cases were considered, which percentage was $7 \%$ of the lactating cows. The impact of mastitis was estimated as being the total in losses added of expenses on both prevention and treatment of clinic cases. Increased bulk tank somatic cell count influenced directly the economic impact of mastitis. The high economic impact highlights the need for monitoring of clinic and subclinical mastitis and adoption of preventive measures to decrease the impacts. The expenses on preventive treatment represents, in the maximum, $10.8 \%$ of the economic impact which demonstrates advantages in investing on that practice, once it will contribute significantly to the decrease of bulk tank SCC and, consequently to reduce the economic impact of mastitis.

KEY WORDS: Dairy cattle, saving, quality of milk, animal health, simulation.

\section{INTRODUÇÃO}

O setor leiteiro é um dos mais importantes do agronegócio brasileiro e vem atravessando um período de evolução. As principais mudanças têm sido a implementação da nova legislação para os padrões mínimos de qualidade (IN n ${ }^{\circ} 51 / 2002$ ), o aumento nas exigências de qualidade do leite por

${ }^{2}$ Universidade Federal de Lavras, Departamento de Ciência dos Alimentos, Lavras, MG, Brasil.

*Bolsista do CNPq.

**Pós-graduando em Ciências Veterinárias, bolsista da CAPES.

***Graduando do curso de Zootecnia. 
parte das indústrias, além de bonificação pelo leite de alta qualidade (Álvares, 2005).

A contagem de células somáticas no tanque (CCST) constitui um importante recurso para o monitoramento da qualidade do leite e da saúde da glândula mamária nos rebanhos, por indicar a ocorrência de mastite subclínica e de possíveis perdas econômicas dela decorrentes (SANTOS; FONSECA, 2007). Para o produtor, a mastite se torna um motivo de preocupação devido à diminuição da produção de leite que, segundo SOMMERHAUSER et al. (2003), a contínua ação dos micro-organismos sobre a mucosa provoca perda progressiva do epitélio secretor diminuindo, assim, a produção de leite. CARVALHO et al. (2007) salientaram que, para a indústria, esse parâmetro se torna importante, porque altas contagens de células somáticas estão associadas a quedas no rendimento, na produção de derivados e a alterações organolépticas no leite e derivados, bem como à redução na vida de prateleira.

Devidoà grande importância da mastite, diversos pesquisadores têm estudado diferentes aspectos, tais como: incidência de casos clínicos (BUENo et al. 2002; Ribeiro et al. 2006), contagem de células somáticas e redução na produção (NATIONAL..., 1996; SILVA et al. 2002), descarte de vacas em virtude de mastite (CONGLETON; KING, 1984;SILvaetal., 2008), prevalência, incidência e frequência de casos clínicos (BUENoet al., 2002; SANTOS; FONSECA, 2007) e influência das células somáticas na qualidade do leite (SANTOS; FONSECA, 2007). No entanto, raras são as pesquisas referentes ao impacto econômico e, nas poucas encontradas na literatura que abordam o assunto, não há detalhamento em relação aos indicadores técnicose gerenciais adotados, para avaliar o impacto econômico da mastite. Considerando os aspectos apresentados, bem como a importância do tema, realizou-se esta pesquisa, cujo objetivo foi analisar e quantificar a influência da contagem de células somáticas no impacto da mastite em rebanhos leiteiros.

\section{MATERIAL E MÉTODOS}

A pesquisa foi conduzida no Laboratório de Informática Aplicada à Produção Animal (LIA) do Departamento de Medicina Veterinária da Universidade Federal de Lavras, por meio de simulação de dados, utilizando o sistema computacional: "CU\$TO MASTITE” (Lopes et al., 2007). A quantidade de amostras para cultura e antibiograma, realizadas anualmente, foi estimada utilizando-se o comando "Stacalc", do Software Epi Info 6.04, de janeiro de 2001. A população a ser amostrada no Epi info foi obtida por meio da multiplicação da quantidade de tetos (quatro) pela quantidade de animais. Para este estudo, foi determinada uma população de 50,100 e
150 animais para 200,400 e 600 tetos, respectivamente. A prevalência considerada para estimar a amostra foi de $20 \%$ (NADER FilHo, 1984), uma vez que esse valor tem sido o mínimo encontrado no Brasil. A confiabilidade adotada foi de $95 \%$. De acordo com a quantidade de animais no rebanho (50, 100 e 150), obtiveram-se, então, as determinações de amostras, que foram de 18, 21 e 23, respectivamente.

As variáveis utilizadas (Fig. 1), bem como os seus respectivos valores, foram: quantidade de vacas em lactação (100 vacas); percentual de vacas secas (33\%); produção diária por animal $(20 \mathrm{~kg})$; frequência de ordenhas/dia (2); intervalo de partos (15 meses); frequência de casos clínicos (1\%); quantidade de doses de vacina para vaca seca (3); percentual de descarte devido a mastite (4\%); percentuais de morte em virtude da mastite/ano (1\%); valor de aquisição da vaca $(R \$ 3.000,00)$ e o valor da vaca a ser descartada $(\mathrm{R} \$ 1.314,00)$. Os valores de contagem de células somáticas no tanque (CCST) selecionados para simulação foram: 250.000; 500.000; 750.000 e 1.000 .000 células somáticas $/ \mathrm{mL}$. Esses valores foram selecionados devido às perdas ocorridas, estimadas em 0; 6 e 18\%, respectivamente, para CCST de 200.000; 500.000 e 1.000.000 (NMC, 1996). Os valores de 250.000 e 750.000 células somáticas/mL foram estimados a partir de uma análise de regressão linear. Para estimar o valor do impacto econômico em decorrência da CCST foi considerado o valor pago no laticínio da Cooperativa Alto Rio Grande, no Município de Lavras, no mês de novembro de 2008. Tal laticínio penalizava os pecuaristas em $R \$ 0,005$ / $\mathrm{kg}$ de leite, quando a CCST era superior a 750.000 células $/ \mathrm{mL}$ e bonificava em $\mathrm{R} \$ 0,005 / \mathrm{kg}$ de leite quando a CCST era inferior a 250.000 células $/ \mathrm{mL}$. Quando essa variou de 500.000 a 750.000 células/ $\mathrm{mL}$ o valor pago por $\mathrm{kg}$ de leite foi de $\mathrm{R} \$ 0,67 / \mathrm{kg}$ de leite, valor tido como base. $\mathrm{O}$ valor considerado para a conversão em dólar foi de $\mathrm{R} \$ 2,25$.

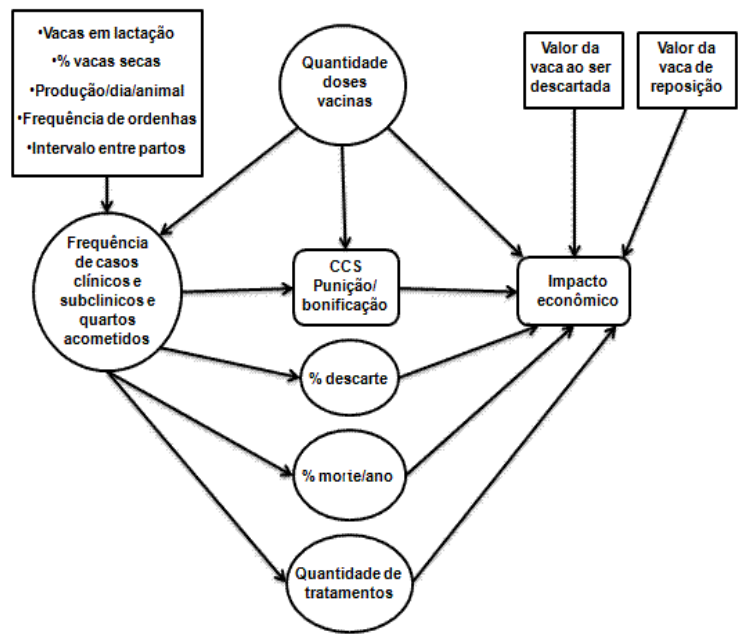

Fig. 1 - Diagrama de influência utilizado nesta pesquisa. 
Foram considerados como custos de prevenção as despesas com monitoramento (cultura e antibiograma, CCST e CCSI, realizados anualmente.), pré e pós-dipping, vacinação, tratamento de vacas secas e manutenção de ordenhadeira. Como medidas curativas, considerou-se apenas os tratamentos com casos clínicos (5 dias), cuja percentagem foi de 7\% das vacas em lactação, sendo que $75 \%$ dos casos clínicos eram apresentados na forma subaguda e $25 \%$, na aguda.

Para a estimativa de casos subagudos foram consideradas as despesas com o tratamento, por meio da soma dos antibióticos locais aplicados (três dias) e mão-de-obra utilizada para realizar essa atividade (10 minutos por teto acometido, com valor unitário de $\mathrm{R} \$ 0,04)$. O valor estimado para caso agudo resultou da soma dos gastos para tratamento local e sistêmico por um período de cinco dias. Foram considerados os valores de mão-de-obra, seringa e agulha, para realização do tratamento sistêmico.

O impacto da mastite (IM) foi considerado como sendo:

$\mathrm{IM}=$ Total em perdas + medidas preventivas + tratamento, onde:

Total de perdas $=$ perdas em leite (redução na produção e descarte de leite durante o tratamento e período de carência do antibiótico);

Medidas preventivas $=$ despesas com antibiograma e cultura + CCST + CMT + pré-dipping + pós-dipping + tratamento de vacas secas + vacinação de vacas secas + manutenção de ordenhadeira;

Tratamento $=$ despesas com aplicação do antibiótico local + antibiótico sistêmico + anti-inflamatório. $\mathrm{O}$ valor estimado para caso agudo resultou da soma dos gastos para tratamento local e sistêmico por um período decinco dias. Foram considerados os valores de mão-de-obra, seringa e agulha, para realização do tratamento sistêmico.

As perdas de leite foram quantificadas a partir de regressão linear (NATIONAL..., 1996):

$y=-4,7908+0,0226 x$, na qual " $y$ " é a porcentagem de perda de leite e " $x$ " a contagem de células somáticas.

\section{RESULTADOS E DISCUSSÃO}

A avaliação do impacto econômico anual da mastite, tomando por referência uma vaca em lactação, variou de $\mathrm{R} \$ 1.333,90$ a $\mathrm{R} \$ 2.145,89$ e de $\mathrm{R} \$ 0,2146$ a $\mathrm{R} \$$ 0,4311/ kg de leite, para CCST de 250.000 e 1.000 .000 de células por $\mathrm{mL}$ de leite, respectivamente (Tabela 1). As diferenças são em virtude da diminuição na produção estimadas em $0 \% ; 6 \% ; 12 \%$ e $18 \%$, respectivamente, para CCST de 200.000; 500.000; 750.000 e 1.000.000 (NATiONAL..., 1996), devido à presença de mastite subclínica e menor preço pago pela indústria. Indexado ao dólar americano, o impacto econômico por vaca em lactação/ano foi estimado em US\$592,84 a US\$953,73 para CCST de 250.000 e $1.000 .000 / \mathrm{mL}$, respectivamente. Esses valores foram consideravelmente superiores aos obtidos por Holanda JUNIOR et al. (2005) (US\$126,00). No entanto, esses pesquisadores não consideraram a mortalidade de vacas devido à mastite, nem houve menção do nível de CCST e não há detalhamento do que foi incluído como custos de prevenção. Tais fatos podem justificar a diferença nos valores.

Os valores observados neste estudo, para CCST até $750.000 / \mathrm{mL}$, relacionados à redução na produção por vaca em lactação, ocasionada pela mastite subclínica, foram de R $\$ 42,34$ (US\$ 18,82); R \$ 318,36 (US\$ 141,49); R\$ 594,71 (US\$ 264,31); inferiores aos observados por CostA et al. (1999), ao relatarem que, no Brasil, somente as perdas com mastite subclínica podem chegar a US\$317,38/vaca.

O custo operacional efetivo das medidas de prevenção, por $\mathrm{kg}$ de leite, apresentou variação de $\mathrm{R} \$ 0,0231$ a $\mathrm{R} \$ 0,0289$ (CCST de 250.000 e 1.000 .000 de células somáticas $/ \mathrm{mL})$, enquanto que os das medidas curativas foram estimados em $\mathrm{R} \$ 0,0544$ a $R \$ 0,0680$, para os mesmos valores de CCST. A diferença nos valores por $\mathrm{kg}$ de leite foi devido à maior quantidade de leite comercializado, pois, à medida que houve aumento da CCST verifica-se a redução na produção, o que ocasionou maior impacto por $\mathrm{kg}$ de leite, o que onerou também os custos com prevenção. Tal fato demonstra que as medidas preventivas, que muitos julgam serem onerosas, trabalhosas e desnecessárias, mostram-se de excelente relação custo/beneficio, corroborando com os resultados obtidos por Oliveira et al. (2007) que, ao acompanharem a implantação de programa de mastite, verificaram que para cada $R \$ 1,00$ de investimento houve retorno de $\mathrm{R} \$ 2,90$ a $\mathrm{R} \$ 5,30$ de renda adicional. Tais pesquisadores salientaram que essa relação custo/benefício foi atribuída à queda da incidência de mastite que, no início do experimento, apresentavam variação de $10,5 \%$ a $26 \%$ para mastite subclínica e, no final, foram observadas variações de $4 \%$ a $11 \%$. A mastiteclínica também apresentou efeito direto, pois, da variação de 5,0\% a 8,0\% no início do experimento caiu para 2,5\% no final das observações. Esses dados da eficiência dos programas de controle de mastite são reflexo da diminuição dos custos com gastos com casos clínicos (em especial) não exigindo tratamentos emergenciais e ônus com o descarte de leite, reposição e morte de animais.

O tratamento curativo de uma vaca com mastite, apresentando sintomas clínicos da doença, foi de R $\$$ 28,68 (US\$12,74) para cada caso subagudo e de R \$ 110,43 (US\$ 49,08) para casos considerados agudos (Tabela 1). Tais valores estão abaixo dos encontrados por BAR et al. (2008), que foi de US\$179,00 e no caso de mastite considerado agudo acima dos 
encontrados por Hoblett et al. (1991), citados por Degraves; Fetrow (1993), que foi de US\$ 107,00 por caso de mastite no rebanho. No primeiro estudo, os pesquisadores consideraram sete possibilidades para casos de mastite, dentre as quais a ocorrência de primeiro e segundo caso de mastite e, também, a expectativa de redução na lactação seguinte. No segundo estudo, os pesquisadores não mencionam esses detalhes.

Quando foi considerado o custo do tratamento curativo de uma vaca em lactação/ano, esse valor foi estimado em $\mathrm{R} \$ 338,39$, o que corresponde a US $\$$ 150,40 (Tabela 1), para todos os casos estudados. Esse valor é inferior ao obtido no estudo de KIRK; BARTLETT (1988), que estimaram os custos em US\$ 163,00 . Naquele estudo, os pesquisadores verificaram incidência de mastite clínica em torno de 16,8\%, maior que a frequência de $15 \%$, adotada nas simulações. Vale salientar que os pesquisadores citados não avaliaram as estimativas de perdas por mastite subclínica e descarte dos animais cronicamente acometidos, o que pode ter subestimado o valor encontrado. Os valores também foram superiores aos observado por BAR et al. (2008), de US\$ 71,00 por vaca, não havendo menção se foi vaca em lactação ou rebanho (vacas em lactação + vacas secas). Outra explicação para os menores valores encontrados pode ser devida às perdas por CCST, que os pesquisadores encontraram 225.000 células somáticas $/ \mathrm{mL}$ e, no estudo em questão, foi de 500.000 células/mL.

O custo com a prevenção de mastite por vaca em lactação/ano, de R $\$ 143,63$ (US $\$ 63,84$ ), foi inferior ao custo com tratamento curativo, que foi de $\mathrm{R} \$ 338,39$ (US\$150,40). Esses valores foram obtidos a partir da divisão do valor total estimado, por ano, para o tratamento preventivo e/ou curativo pela quantidade de vacas em lactação no rebanho. Pode-se verificar que o percentual do item prevenção apresentou diminuição à medida que aumentou à CCST, indicador de aumento de mastite subclínica no rebanho. Vale salientar que o valor absoluto empregado, de $\mathrm{R}$ \$ 14.362,55 (Tabela 2), não se alterou em nenhum dos casos estudados. A diferença dos percentuais ocorreu devido à alteração de valores em outros itens que, de acordo com o nível de CCST, assume maior proporção. Essa mudança no percentual foi devida às perdas de leite, que são reflexo da maior incidência de mastite subclínica.

Tabela 1 - Avaliação do impacto econômico da mastite, por kg de leite, vaca em lactação e rebanho* (vacas em lactação + vacas secas), em R\$, em função da contagem de células somáticas no tanque.

\begin{tabular}{|c|c|c|c|c|}
\hline \multirow{3}{*}{ Especificação } & \multicolumn{4}{|c|}{ Contagem de células somáticas no tanque $(x 1.000 / \mathrm{mL})$} \\
\hline & 250 & 500 & 750 & 1.000 \\
\hline & \multicolumn{4}{|c|}{$\mathrm{R} \$$} \\
\hline COE da prevenção/kg de leite produzido & 0,0231 & 0,0248 & 0,0266 & 0,0289 \\
\hline COE do tratamento curativo $/ \mathrm{kg}$ de leite produzido & 0,0544 & 0,0583 & 0,0628 & 0,0680 \\
\hline $\begin{array}{l}\text { COE do tratamento preventivo + curativo } / \mathrm{kg} \text { de leite pro- } \\
\text { duzido }\end{array}$ & 0,0776 & 0,0831 & 0,0894 & 0,0968 \\
\hline Perdas de produção/kg de leite produzido & 0,1371 & 0,1935 & 0,2596 & 0,3343 \\
\hline Impacto econômico $/ \mathrm{kg}$ de leite & 0,2146 & 0,2766 & 0,3490 & 0,4311 \\
\hline COE do tratamento curativo de caso subagudo/vaca afetada & 28,68 & 28,68 & 28,68 & 28,68 \\
\hline COE do tratamento curativo de caso agudo/vaca afetada & 110,43 & 110,43 & 110,43 & 110,43 \\
\hline COE da prevenção/vaca em lactação/ano & 143,63 & 143,63 & 143,63 & 143,63 \\
\hline $\begin{array}{l}\text { COE da prevenção/rebanho (vacas lactação + vacas secas)/ } \\
\text { ano }\end{array}$ & 107,99 & 107,99 & 107,99 & 107,99 \\
\hline $\begin{array}{l}\text { COE do tratamento curativo (caso subagudo + agudo)/vaca } \\
\text { em lactação/ano }\end{array}$ & 338,39 & 338,39 & 338,39 & 338,39 \\
\hline $\begin{array}{l}\text { COE do tratamento prev + curativo (caso subagudo + agudo)/ } \\
\text { vaca em lactação/ano }\end{array}$ & 482,02 & 482,02 & 482,02 & 482,02 \\
\hline $\begin{array}{l}\text { Perdas de leite (redução na produção+ descarte)/vaca em } \\
\text { lactação/ano }\end{array}$ & 851,88 & $1.122,80$ & $1.399,14$ & $1.663,87$ \\
\hline Impacto econômico/vaca em lactação/ano & $1.333,90$ & $1.604,82$ & $1.881,16$ & $2.145,89$ \\
\hline${ }^{1}$ Impacto econômico total (perdas + despesas)/ano & $133.390,03$ & $160.481,82$ & $188.115,97$ & $214.589,08$ \\
\hline \multicolumn{5}{|c|}{ *Rebanhos de 100 vacas holandesas em lactação, com produção diária de 20 kg. } \\
\hline \multicolumn{5}{|c|}{$\begin{array}{l}\mathrm{COE}=\text { custo operacional efetivo; }{ }^{1} \text { Impacto econômico total: gastos com prevenção, tratamento curativo, perdas em } \\
\text { virtude da redução na produção dos animais acometidos por mastite e descarte de leite dos animais em tratamento. } \\
\text { Valores dos insumos e produtos utilizados foram obtidos no comércio local de Lavras, em novembro de } 2008 \text {. } \\
\text { 'Valor do kg de leite considerado para estimar as perdas foi de } \mathrm{R} \$ 0,675, \mathrm{R} \$ 0,670, \mathrm{R} \$ 0,670 \text { e } \mathrm{R} \$ 0,665 \text {, respectivamente, } \\
\text { para CCST de } 250.000 ; 500.000 ; 750.000 \text { e } 1.000 .000 \text { de células somáticas por mL de leite. Esses valores foram obtidos na } \\
\text { Cooperativa Agrícola Alto Rio Grande, no Município de Lavras, em novembro de } 2008 \text {. }\end{array}$} \\
\hline
\end{tabular}


A receita bruta proveniente do leite diminuiu à medida que houve aumento da CCST, indicador de aumento da mastite subclínica no rebanho. Tal fato foi devido principalmente à queda de produção devido à doença, mas também ocasionado pela penalização de $\mathrm{R} \$ 0,005 / \mathrm{kg}$ de leite comercializado, quando a CCST foi acima de 750.000 células somáticas $/ \mathrm{mL}$. Quando essa foi até 250.000 células somáticas/mL houve uma bonificação de $\mathrm{R} \$ 0,005 / \mathrm{kg}$ de leite; de 500.000 a 750.000 células somáticas/mL não houve alteração (nem bonificação e nem penalização) no valor pago por $\mathrm{kg}$ de leite. LOPEs et al. (2006b) constataram que parte significativa da renda na atividade leiteira é devido à maior escala e à bonificação recebida pelas maiores produções. Neste trabalho a bonificação foi de $\mathrm{R} \$ 0,01 / \mathrm{kg}$ de leite comercializado, quando a produção diária foi maior que 1.001 até $2.000 \mathrm{~kg} /$ dia. A bonificação é um incentivo que tem por finalidade atender a instrução normativa $\mathrm{n}^{\circ} 51$ de 18/09/2002 (BRASIL, 2002) que, a partir de 1 de julho de 2008, determinou que o leite proveniente das regiões Sudeste, Sule Centro Oeste devem conter CCST máxima de $750.000 / \mathrm{mL}$. A indústria possui grande interesse no aumento da qualidade, visto que altas contagens de células somáticas estão associadas a quedas no rendimento na produção de derivados, a alterações organolépticas no leite e derivados e à redução na vida de prateleira (SANTOS et al., 2003). A bonificação é concedida a produtores que fornecem leite com baixa CCST, um incentivo que deve existir, uma vez que a produção de leite com baixa CCST apresenta maior rendimento de lácteos de melhor qualidade. A penalização ocorre porque leite que apresenta baixa qualidade, devido à alta CCST, apresenta menor rendimento na produção de lácteos, menor tempo de prateleira e, por fim, menor lucratividade na indústria láctea.

Quanto à venda de animais, não há indicação na literatura de qual percentual seria o ideal para esses valores. No entanto, essas estimativas são pequenas, quando comparadas aos valores obtidos por Lopes et al. (2008), que encontraram $7,55 \% ; 16,26 \%$ e $3,14 \%$ e Lopes et al. (2006a), que foi de $20,29 \% ; 7,29 \%$ e $9,70 \%$ para pequenos, médios e grandes produtores. A diferença dos percentuais se deve ao fato de que, neste estudo, foi considerado somente o descarte involuntário por mastite, enquanto nos outros estudos mencionados foram considerados todas as vendas de animais, o que possibilita maior receita. Lopes et al. (2009a) encontraram $15 \%$ a $20 \%$ da receita bruta proveniente da venda de animais, o que também está bem acima dos resultados observados neste estudo.

Os percentuais de prevenção, em relação à renda bruta, foram estimados em 3,37\%; 3,63\%; 3,90\% e $4,25 \%$, enquanto que os referentes ao tratamento curativo $7,93 \% ; 8,55 \% ; 9,19 \%$ e $10,01 \%$ para CCST de 250.000;500.000;750.000 e 1.000.000, respectivamente.
As perdas totais apresentaram o maior impacto percentual em relação à renda bruta do sistema de produção estão na Tabela 2.

\section{CONCLUSÕES}

O aumento da CCST influenciou diretamente o impacto econômico da mastite. $\mathrm{O}$ item de maior representatividade no impacto econômico foram as perdas ocasionadas pela diminuição na produção, seguido do descarte deleite de animais em tratamento e despesas com tratamento curativo. As despesas com tratamento preventivo representaram, no máximo, 10,8\% do impacto econômico, o que demonstra vantagens em investir nessa prática.

\section{REFERÊNCIAS}

ÁLVARES, J.G. Pagamento do leite por sólidos. In: VISÃO TÉCNICA E ECONÔMICA DA PRODUÇÃO LEITEIRA, 5., 2005, Piracicaba, SP. Anais, Piracicaba: FEALQ, 2005. p.129-140.

BAR, D.; TAUER, L.W.; BENNETT, G.; GONZALEZ, R.N.; HERTL, J.A.; SCHUKKEN, Y.H.; SCHULTE, H.F.; WELCOME, F.L.; GRÖHN, Y.T. The cost of generic clinical mastitis in dairy cows as estimated by using dynamic programming. Journal of Dairy Science, v. 91, n.6, p.2205-2214, 2008.

BRASIL. Instrução Normativa ${ }^{\circ}$ 51, de 18 de setembro de 2002. Estabelece o regulamento fixar os requisitos mínimos que devem ser observados para a produção, a identidade e a qualidade do leite. Diário Oficial [da] República Federativa do Brasil, Brasília, p. 13-22, 18 set. 2002. Seção I.

BUENO, V.F.F.; NICOLAU, E.S.; MESQUITA, A.J.; RIBEIRO, A.R.; SILVA, J.A.B.; COSTA, E.O.; COELHO, K.O.; NEVES, R.B.S. Mastite bovina clínica e subclínica, na região de Pirassununga, SP: frequências e redução na produção. Ciência Animal Brasileira, v.3, n.2, p. 47-52, 2002.

CARVALHO, L.B.; AMARAL, F.R.; BRITO, M.A.V.P.; LANGE, C.C.; BRITO, J.RF.; LEITE, R.C. Contagem de células somáticas e isolamento de agentes causadores de mastite em búfalas (bubalus bubalis). Arquivo Brasileiro de Medicina Veterinária e Zootecnia, v.59, n.1, p.242-245, 2007.

CONGLETON, W.R.; KING, L.W. Profitability of dairy cow herd life. Journal of Dairy Science, v.67, n.3, p.661674, 1984.

COSTA, E.O.; RIBEIRO, A.R.; WATANABE, E.T.

Mastite sub-clínica: prejuízos causados e os custos de prevenção em propriedades leiteiras. Napgama, v.2, n.2, p.16-20, 1999. 
COSTA, E.O.; MOTA, R.; SANTOS, F.G.B. Contagem de células somáticas de amostras de leite de glândulas mamárias de fêmeas bovinas em lactação infectadas por microrganismos dos gêneros Streptococcus, Staphylococcus e Corynebacterium. Napgama, v.8, n.2, p.3-7, 2005.

DEGRAVES, F.J.; FETROW, J. Economics of mastitis and mastitis control. The Veterinary Clinics of North America. Food Animal Practice, v.9, n.3, p.421-434, 1993.

HOBLET, K.H. Costs associated with selected preventive practices and with episodes of clinical mastitis in nine herds with low somatic cell counts. Journal of the American Veterinary Medicine Association, v.199, n.2, p.190-196, 1991.

HOLANDA JUNIOR, E.V.; MADALENA, F.E.; HOLANDA, E.D.; MIRANDA, W.M.; SOUZA, M.R. Impacto econômico da mastite em seis fazendas de Araxá - Minas Gerais, Brasil. Archivos Latinoamericanos de Produção Animal, v.13, n.2, p.63-69, 2005.

KIRK, J.H.; BARTLETT, P.C. Economic impact of mastits in Michigan Hostein dairy herss using a computerized records system. Agri-Practice, v.9, n.1, p.3-6, 1988.

LOPES, M.A.; CARDOSO, M.G.; CARVALHO, F.M.; LIMA, A.L.R.; DIAS, A.S.; CARMO, E.A. Efeito do tipo de sistema de criação nos resultados econômicos de sistemas de produção de leite na região de Lavras (MG) nos anos 2004 e 2005. Ciência Animal Brasileira, v.8, n.3, p.359-371, 2007.

LOPES, M.A.; CARMO, E.A.; LIMA, A.L.R.; CARVALHO, F.M. Análise da rentabilidadede uma empresa com opção de comercialização de queijo ou leite. Arquivo Brasileiro de Medicina Veterinária e Zootecnia, v.58, n.4, p.642-647, 2006a.

LOPES, M.A.; LIMA, A.L.R.; CARVALHO, F. de M.; REIS, R.P.; SANTOS, I.C.; SARAIVA, F.H. Efeito da escala de produção nos resultados econômicos de sistemas de produção de leite na região de Lavras (MG): um estudo multicasos. Boletim de Indústria Animal, v.63, n.3, p.177-188, 2006b.

LOPES, M.A.; SANTOS, G.; COSTA, G.M.; LOPES, N.M. Desenvolvimento de um sistema computacional para avaliar o impacto econômico da mamite em rebanhos leiteiros. In: CONGRESSO BRASILEIRO DE AGROINFORMÁTICA, 6., 2007, São Pedro. Anais. São Pedro, 2007. 5p. 1-CDRoom.

LOPES, M.A.; CARDOSO, M.G.; CARVALHO, F.M.; LIMA, A.L.R.; DIAS, A.S.; CARMO, E.A. Resultados econômicos da atividade leiteira na região de Lavras (MG) nos anos 2004 e 2005: um estudo multicasos. Arquivo Brasileiro de Veterinária e Zootecnia, v.60, n.2, p.428-435, 2008.
LOPES, M.A.; CARDOSO, M.G.; DEMEU, F.A. Influência de diferentes índices zootécnicos na composição e evolução de rebanhos bovinos leiteiros. Ciência Animal Brasileira, v.10, n.2, p.446-453, 2009a.

LOPES, M.A.; DIAS, A.S.; CARVALHO, F.M.; LIMA, A.L.R.; CARDOSO, M.G.; CARMO, E.A. Resultados econômicos de sistemas de produção de leite com diferentes níveis tecnológicos na região de Lavras MG nos anos de 2004 e 2005. Ciência e Agrotecnologia, v.33, n.1, p.252-260, 2009b.

NADER FILHO, A. Estudo da variação do ponto crioscópico do leite de búfala. Revista do Instituto de Laticínios Cândido Tostes, v.39, p.234, 1984.

NATIONAL MASTITIS COUNCIL. US. Current concepts of bovine mastitis. 4.ed. Madison: NMC, 1996. 64p.

OLIVEIRA, V.M.; CARNEIRO, A.V.; SILVA, M. R. Benefícios de um programa de controle de mastite bovina em condições brasileiras de criação. In: CONGRESSO PAN-AMERICANO DO LEITE, 2006, Porto Alegre. Resumo. Juiz de Fora : Embrapa Gado de Leite, 2006.

RIBEIRO, M.E.R.; PETRINI, L.A.; BARBOSA, R.S.; ZANELA, M.B.; GOMES, J.F.; STUMPF JUNIOR, W.; SCHRAMM, R. Ocorrência de mastite causada por Nocardia spp. em rebanhos de unidades de produção leiteira no sul do rio grande do sul. Revista Brasileira de Agrociência, v.12, n.4, p.471-473, 2006.

SANTOS, MV.; FONSECA, L.F.L. Estratégias para controle de mastite e melhoria da qualidade do leite. São Paulo: Manole, 2007. 313 p.

SANTOS, M.V.; MA, Y.; BARBANO, D.M. Effect of somatic cell count on proteolysis and lipolysis in pasteurized fluid milk during shelf-life storage. Journal of Dairy Science, v.86, n.8, p.2491-2503, 2003.

SILVA, F.C.; BERGAMASCO, A.F.; VENDITE, L.L. Modelos de simulação para análise e apoio à decisão em agrossistemas. Revista Biociências, v.8, n.2, p.7-17, 2002.

SILVA, L.A.F.; COELHO, K.O.; MACHADO, P.F.; SILVA, M.A.M.; MOURA, M.I.; BARBOSA, V.T.; GOULART, M.M.; GOULART, D.S. Causas de descarte de vacas da raça holandesa confinadas em uma população de 2.083 bovinos (2000-2003). Ciência Animal Brasileira, v.9, n.2, p.383-389, 2008.

SOMMERHAUSER, J.; KLOPPERT, B.; WOLTER, W.; ZSCHOCK, M.; SOBIRAJ, A.; FAILING K. The epidemiology of Staphylococcus aureus infections from subclinical mastitis in dairy cows during a control programme. Veterinary Microbiology, v.96, p.91-102, 2003.

Recebido em 11/4/11

Aceito em 1/11/11 